\title{
Chemical-Kinetic Characterization of Autoignition and Combustion of Surrogate Diesel
}

\author{
K. Seshadri
}

March 3, 2003

U.S. Department of Energy

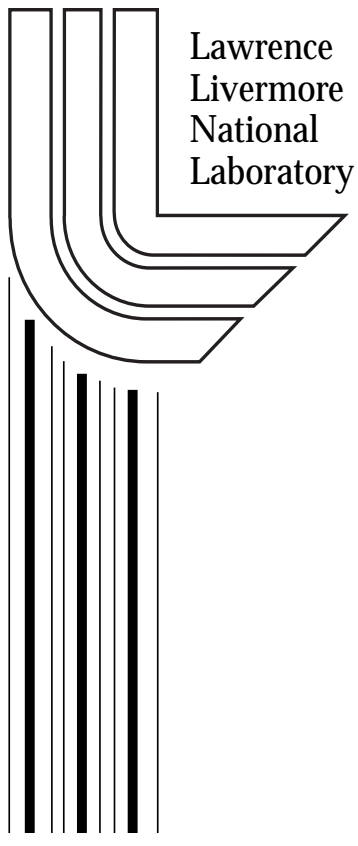




\section{DISCLAIMER}

This document was prepared as an account of work sponsored by an agency of the United States Government. Neither the United States Government nor the University of California nor any of their employees, makes any warranty, express or implied, or assumes any legal liability or responsibility for the accuracy, completeness, or usefulness of any information, apparatus, product, or process disclosed, or represents that its use would not infringe privately owned rights. Reference herein to any specific commercial product, process, or service by trade name, trademark, manufacturer, or otherwise, does not necessarily constitute or imply its endorsement, recommendation, or favoring by the United States Government or the University of California. The views and opinions of authors expressed herein do not necessarily state or reflect those of the United States Government or the University of California, and shall not be used for advertising or product endorsement purposes.

This work was performed under the auspices of the U. S. Department of Energy by the University of California, Lawrence Livermore National Laboratory under Contract No. W-7405-Eng-48.

This report has been reproduced directly from the best available copy.

Available electronically at http://www.doc.gov/bridge

Available for a processing fee to U.S. Department of Energy

And its contractors in paper from

U.S. Department of Energy

Office of Scientific and Technical Information

P.O. Box 62

Oak Ridge, TN 37831-0062

Telephone: (865) 576-8401

Facsimile: (865) 576-5728

E-mail: reports@adonis.osti.gov

Available for the sale to the public from

U.S. Department of Commerce

National Technical Information Service

5285 Port Royal Road

Springfield, VA 22161

Telephone: (800) 553-6847

Facsimile: (703) 605-6900

E-mail: orders@ntis.fedworld.gov

Online ordering: http://www.ntis.gov/ordering.htm

OR

Lawrence Livermore National Laboratory

Technical Information Department's Digital Library

http://www.llnl.gov/tid/Library.html 
Chemical-Kinetic Characterization of Autoignition and Combustion of Surrogate Diesel

FINAL REPORT

K. SESHADRI

MARCH 3, 2003

MEMORANDUM AGREEMENT NO. B510065

CENTER FOR ENERGY RESEARCH

DEPARTMENT OF MECHANICAL AND AEROSPACE ENGINEERING

UNIVERSITY OF CALIFORNIA AT SAN DIEGO

LA JOLLA, CALIFORNIA 92093-0411 


\section{Contents}

1 Statement of the Problem Studied $\quad 3$

2 Results $\quad 3$

2.1 Shock Tube Comparisons . . . . . . . . . . . . . . . . . . . 3

2.2 Flow Reactor Comparisons . . . . . . . . . . . . . . . . . 5

2.3 Comparisons under Non Premixed Conditions . . . . . . . . . . . . . . . . 7

3 Publications and Technical Reports $\quad 12$

4 Participating Scientific Personnel 12 


\section{Statement of the Problem Studied}

A study was performed to elucidate the chemical-kinetic mechanism of combustion of toluene. The research was performed in collaboration Dr. Charles Westbrook and Dr. William Pitz at Lawrence Livermore National Laboratory (LLNL). A detailed chemical-kinetic mechanism for toluene developed at LLNL was employed. Numerical calculations were performed using this mechanism and the results were compared with experimental data obtained from premixed and nonpremixed systems. Under premixed conditions, predicted ignition delay times were compared with new experimental data obtained by I. Da Costa, R. Fournet, F. Billaud, F. Battin-Leclerc at Département de Chime Physique des Réactions, CNRS-ENSIC, BP. 451, 1, rue Grandville, 51001 Nancy, France. Also, calculated species concentration histories were compared to experimental flow reactor data from the literature. Under nonpremixed conditions, critical conditions of extinction and autoignition were measured in strained laminar flows in the counterflow configuration. Numerical calculations were performed using the chemical-kinetic mechanism at conditions corresponding to those in the experiments. Critical conditions of extinction and autoignition are predicted and compared with the experimental data. Comparisons between the model predictions and experimental results of ignition delay times in shock tube, and extinction and autoignition in nonpremixed systems show that the chemical-kinetic mechanism predicts that toluene/air is overall less reactive than observed in the experiments.

The principal objective of this research is to obtain a fundamental understanding of the physical and chemical mechanisms of autoignition and combustion of Diesel in nonpremixed systems. The major components of Diesel are straight-chain paraffins, branched-chain paraffins, cycloparaffins, and aromatics. The results of this research on toluene are expected to be useful in understanding the role of aromatics in combustion of Diesel.

\section{Results}

The detailed chemical-kinetic mechanism for toluene was obtained from LLNL. The detailed mechanism is made up 349 species and 1631 reversible reactions. Numerical calculations were carried out using this mechanisms. The results were compared with experiments.

\subsection{Shock Tube Comparisons}

Ignition delay times were measured in toluene/O $\mathrm{O}_{2} / \mathrm{Ar}$ mixtures at DCPR-CNRS-NANCY. The experimental data is shown in Fig. 1. The ignition in the shock tube was simulated using the Senkin code [1] assuming constant volume combustion after the reflected shock passes

through the mixture. The measured results are compared to predicted results in Fig. 1. In the 


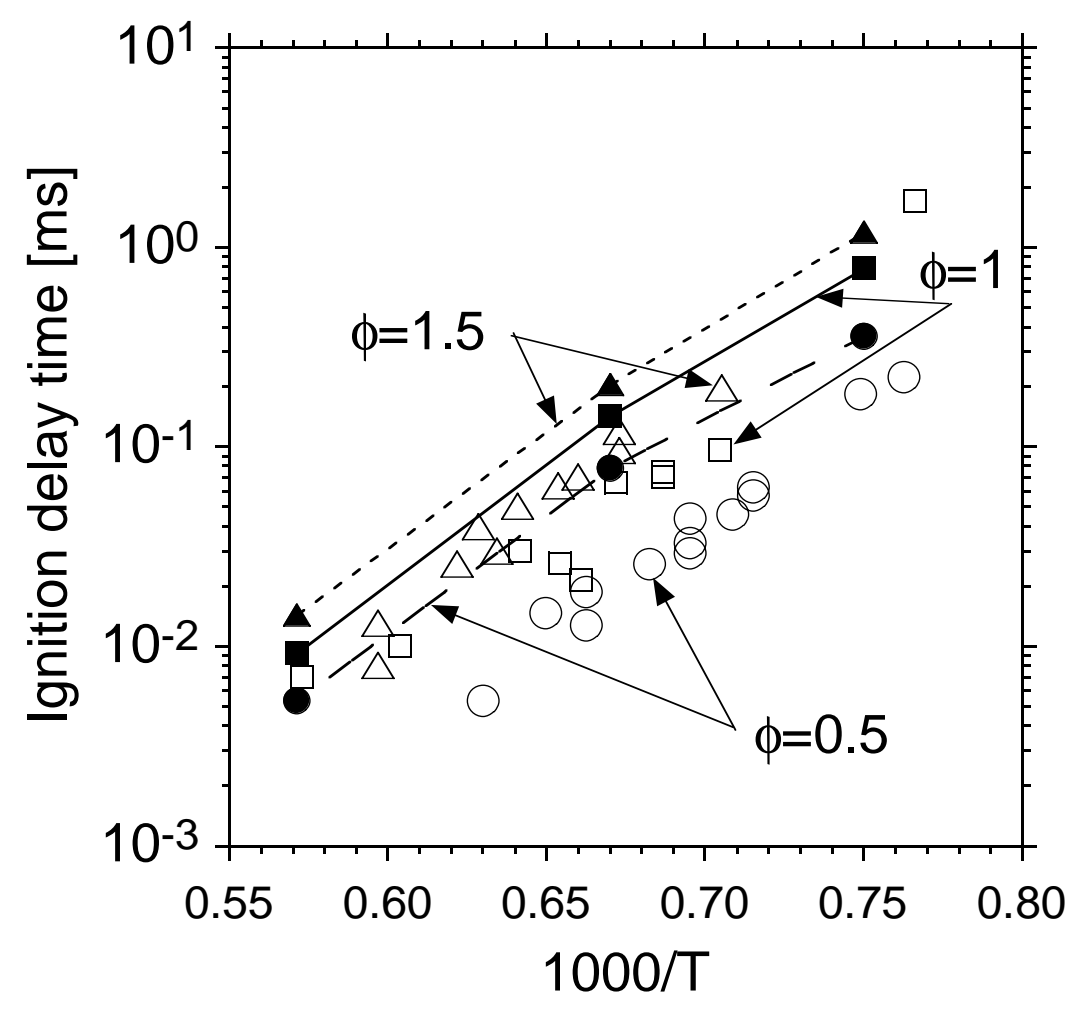

Figure 1: Predicted (lines and filled symbols) and measured (unfilled symbols) ignition delay times of toluene $/ \mathrm{O}_{2} /$ Ar mixtures under shock tube conditions. $(T=$ reflected shock temperature in Kelvin). 
experiments, 10 percent of the maximum $\mathrm{OH}$ emission was used as an indication of ignition. The computed ignition delay time was obtained using the inflection in the temperature profile as an indication of ignition. When 10 percent of the $\mathrm{OH}$ maximum concentration was used in the calculations, almost identical results were obtained over the temperature range considered. We did not attempt to simulate $\mathrm{OH}$ emission. The predicted ignition delay times compared reasonably well with experimental values for the fuel-rich case, but were too long for the fuel-lean case.

\subsection{Flow Reactor Comparisons}

The flow reactor was simulated using the Senkin code [1]. The predicted results are compared to the measurements of Klotz et al. [2] in Figs. 2 and 3. The results of the fuel profile look

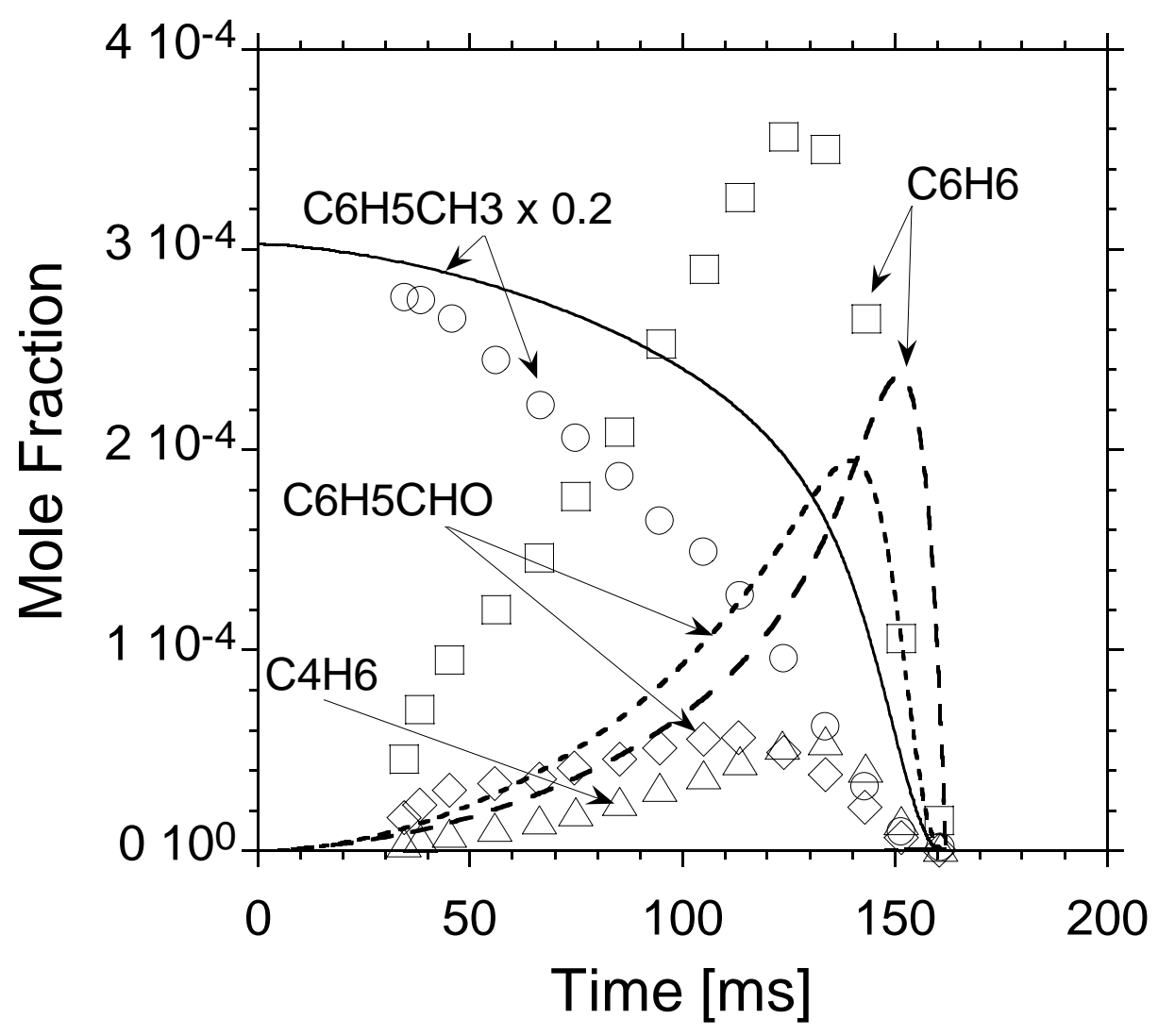

Figure 2: Predicted and measured concentration histories under flow reactor conditions. $(\phi=$ $0.76, \mathrm{~N}_{2} 98 \%$, initial temperature $=1173 \mathrm{~K}$, atmospheric pressure, time is residence time in flow reactor). The symbols represent measurements of Klotz et al. [2]. The lines are results of numerical calculations.

reasonable and the early appearance of the benzylaldehyde peak compared to the benzene 


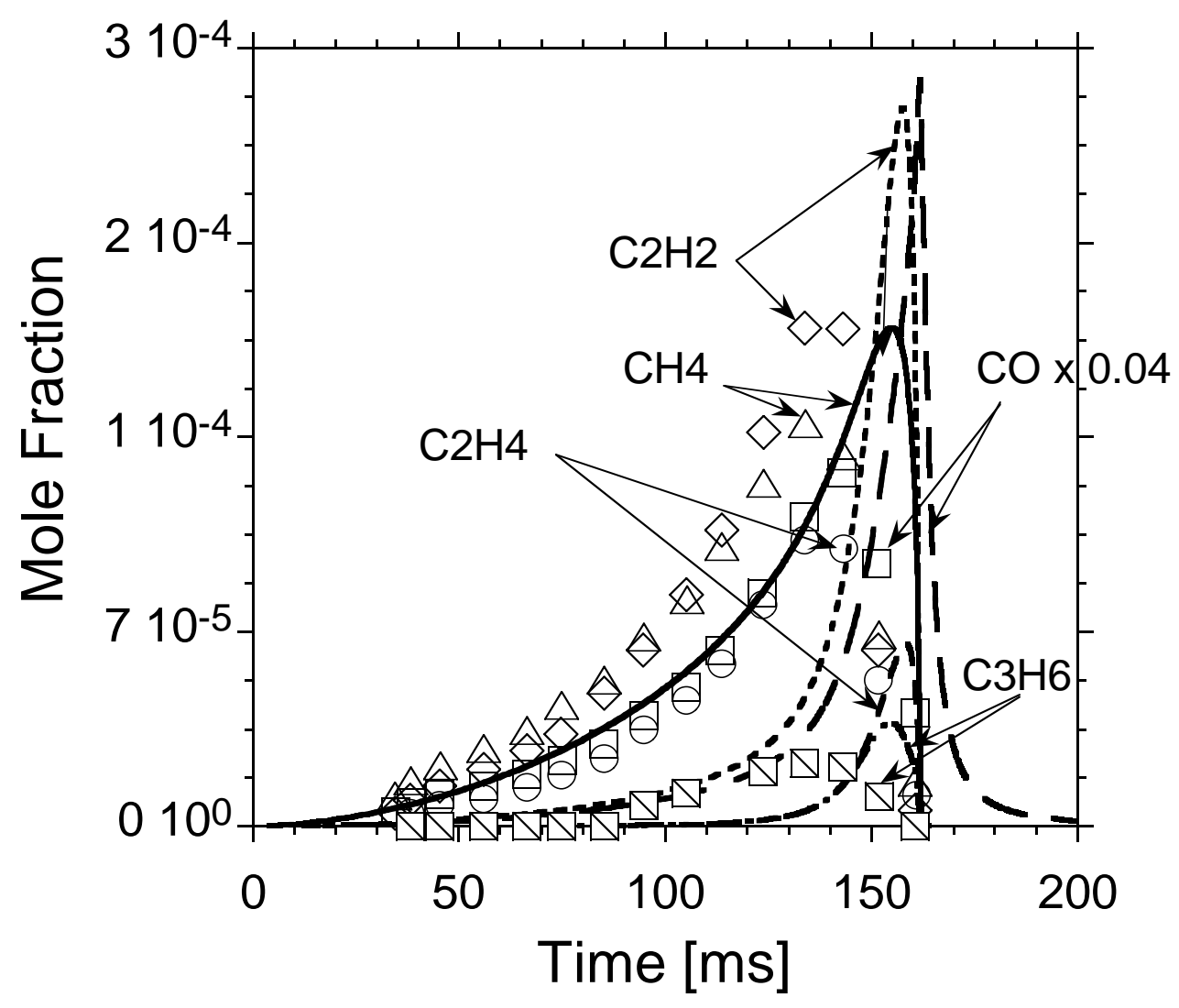

Figure 3: Predicted and measured concentration histories under flow reactor conditions. $(\phi=$ $0.76, \mathrm{~N}_{2} 98 \%$, initial temperature $=1173 \mathrm{~K}$, atmospheric pressure, time is residence time in flow reactor). The symbols represent measurements of Klotz et al. [2]. The lines are results of numerical calculations. 
peak is predicted. Many of the peak intermediate concentrations are predicted within a factor of two of the measurements, except for benzyladehyde which is within a factor of three and 1,3butadiene which is predicted to be in very low concentrations compared to the measurements.

\subsection{Comparisons under Non Premixed Conditions}

Experiments under nonpremixed conditions were carried out in the counterflow configuration. Figure 4 shows a schematic illustration of the counterflow configuration. Steady, axisymmet-

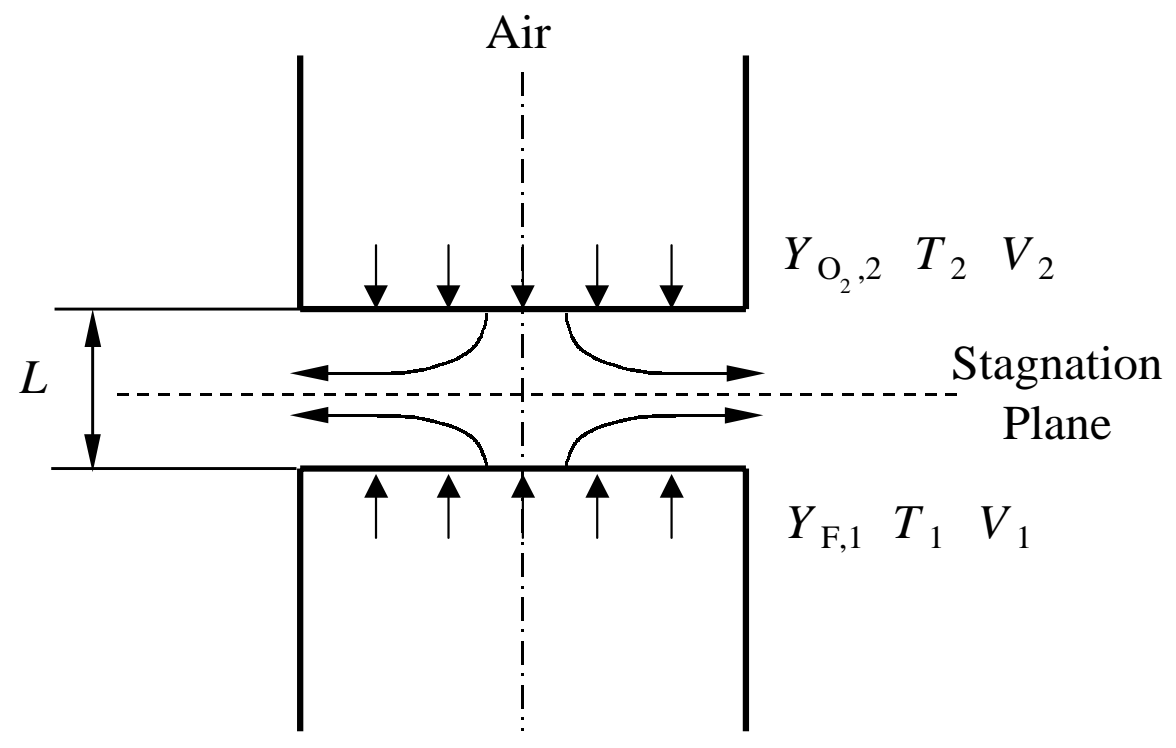

\section{Prevaporized Toluene + Nitrogen}

Figure 4: Schematic illustration of the counterflow configuration.

ric, laminar flow of two counterflowing streams toward a stagnation plane is considered. In this configuration a fuel stream made up of prevaporized toluene and nitrogen is injected from the fuel-duct, and an oxidizer stream of air is injected from the oxidizer-duct. These jets flow into the mixing layer between the two ducts. The exit of the fuel-duct is called the fuel boundary and the exit of the oxidizer-duct the oxidizer boundary. The mass fraction of fuel, the temperature, and the component of the flow velocity normal to the stagnation plane at the fuel boundary are represented by $Y_{\mathrm{F}, 1}, T_{1}$, and $V_{1}$, respectively. The mass fraction of oxygen, the temperature, and the component of the flow velocity normal to the stagnation plane at the oxidizer boundary are represented by $Y_{\mathrm{O}_{2}, 2}, T_{2}$, and $V_{2}$, respectively. The tangential components of the flow velocities at the boundaries are presumed to be equal to zero. The distance between the fuel boundary and the oxidizer boundary is represented by $L$. 
In the experiments the momenta of the counterflowing reactant streams $\rho_{i} V_{i}^{2}, i=1,2$ at the boundaries are kept equal to each other. Here $\rho_{1}$ and $\rho_{2}$ represent the density of the mixture at the fuel boundary and at the oxidizer boundary, respectively. This condition ensures that the stagnation plane formed by the two streams is approximately in the middle of the region between the two boundaries. The value of the strain rate, defined as the normal gradient of the normal component of the flow velocity, changes from the fuel boundary to the oxidizer boundary [3]. The characteristic strain rate on the oxidizer side of the stagnation plane $a_{2}$ is presumed to be given by [3]

$$
a_{2}=\frac{2\left|V_{2}\right|}{L}\left(1+\frac{\left|V_{1}\right| \sqrt{\rho_{1}}}{\left|V_{2}\right| \sqrt{\rho_{2}}}\right) \text {. }
$$

Equation 1 is obtained from an asymptotic theory where the Reynolds numbers of the laminar flow at the boundaries are presumed to be large [3]. Critical conditions of extinction are presumed to be given by the strain rate, $a_{2, e}$, and the mass fraction of fuel at the fuel boundary. Critical conditions of autoignition are presumed to be given by the strain rate, $a_{2, I}$, the temperature of the oxidizer stream, $T_{2, I}$, and the mass fraction of fuel and at the fuel boundary. The experiments were conducted at a pressure of 1.013 bar.

A detailed description of the burner is given elsewhere $[4,5]$. The flow rates of gases were measured by computer-regulated mass flow controllers. The velocities of the reactants at the boundaries were presumed to be equal to the ratio of their volumetric flowrates to the cross-section area of the ducts. The temperature of the fuel stream and the temperature of the oxidizer stream at the boundaries were measured using thermocouples. The measured temperatures were corrected for radiative heat losses. The accuracy of the radiation-corrected temperatures is expected to be $\pm 25 \mathrm{~K}$. A brief description of the experimental procedure is given here.

In the extinction experiments the temperature of the fuel stream, $T_{1}=378 \mathrm{~K}$, and the temperature of the oxidizer stream, $T_{2}=298 \mathrm{~K}$. The distance between the fuel boundary and the oxidizer boundary was $L=10 \mathrm{~mm}$. At some selected value of $Y_{\mathrm{F}, 1}$ the flame was stabilized at $a_{2}<a_{2, e}$. The strain rate was increased by increasing $V_{1}$ and $V_{2}$ until extinction was observed. Experimental results are shown in Fig. 5.

Previous autoignition experiments were conducted with the mole fraction of prevaporized fuel maintained at 0.15 [5]. The temperature at the fuel boundary, $T_{1}=378 \mathrm{~K}$. The distance between the fuel boundary and the oxidizer boundary was $L=12 \mathrm{~mm}$. At a given strain rate and oxidizer temperature $T_{2}<T_{2, I}$ the flow field was established. The temperature at the oxidizer boundary was gradually increased until autoignition took place. Experimental results 
are shown in Fig. 6.

The detailed chemical-kinetic mechanism was tested by comparing computed results with experiments performed under strained, nonpremixed conditions. Numerical calculations were carried out using FlameMaster [6]. The formulation of the numerical problem is summarized elsewhere $[6,7]$. At both ends of the computational domain, the mass fractions of the reactants and the normal components of the flow velocity were specified. The values of the tangential component of the flow velocity at both ends were set equal to zero (the so-called plug-flow boundary conditions). The characteristic strain rate at the stagnation plane was calculated using Eq. (1). Solutions could not be obtained with the 349 species detailed chemical-kinetic mechanism due to numerical "stiffness" problems. The detailed chemical kinetic mechanism was simplified using the NIST XSenkplot [8]. Simplified mechanisms were obtained under shock tube conditions and flow reactor conditions and combined to yield a 58 species mechanism made up of 221 reversible reactions. Any reaction in the detailed mechanism that involved only these 58 species was retained in the simplified mechanism. Ignition delay times were calculated using the simplified mechanism and the detailed mechanism at conditions similar to those employed in the shock-tube experiments. At all conditions the differences were found to be less than $14 \%$.

Figure 5 shows the mass fraction of toluene in the fuel stream at extinction, $Y_{\mathrm{F}, 1}$, as a function of the strain rate, $a_{2, e}$. The symbols represent measurements. The solid line represents results of numerical calculations performed using the simplified chemical-kinetic mechanism. At a given value of $Y_{\mathrm{F}, 1}$ the calculated value of $a_{2, e}$ is lower than that measured. Figure 6 shows the oxidizer temperature at autoignition, as a function of the strain rate, $a_{2, I}$. The symbols represent measurements reproduced from Refs. [5, 9]. The solid line represents results of numerical calculations performed using the simplified chemical-kinetic mechanism. At a given value of the oxidizer temperature the calculated value of $a_{2, I}$ is lower than that measured. Thus in both extinction and ignition experiments, the numerical model predicts that toluene/air is overall less reactive than observed in the experiments. This result is consistent with comparisons between the model predictions and experimental results from the shock tube above $1400 \mathrm{~K}$.

The sensitivity results for autoignition under nonpremixed conditions are given in Fig. 7 . The analysis performed by FlameMaster [6] gives the change in maximum $\mathrm{OH}$ concentration for an incremental change in rate constant as indicated in Fig. 7. In FlameMaster, forward and reverse rate constants are considered as separate parameters for the purposes of sensitivity analysis. The analysis was performed for a reactive flow solution very near autoignition. Positive sensitivities indicate an increase in rate constant increases the $\mathrm{OH}$ concentration and 


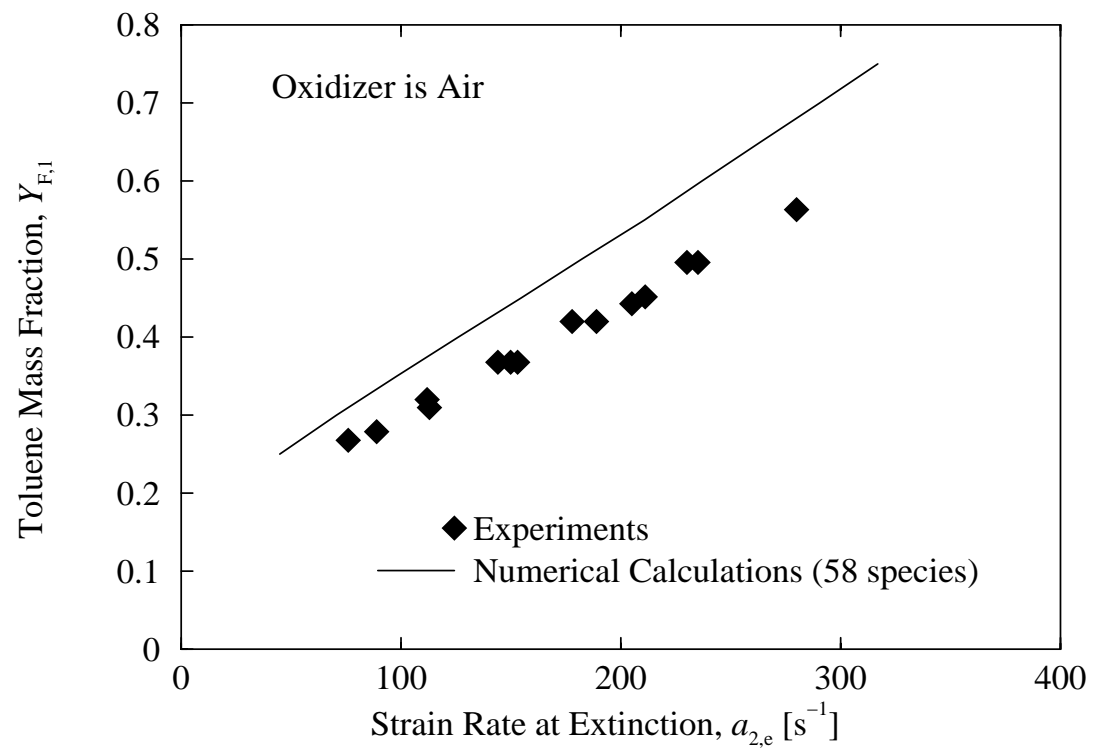

Figure 5: Mass fraction of toluene in the fuel stream at extinction, $Y_{\mathrm{F}, 1}$, as a function of the strain rate, $a_{2, e}$. The symbols represent measurements. The solid line represents results of numerical calculations performed using the simplified chemical-kinetic mechanism made up of 58 species.

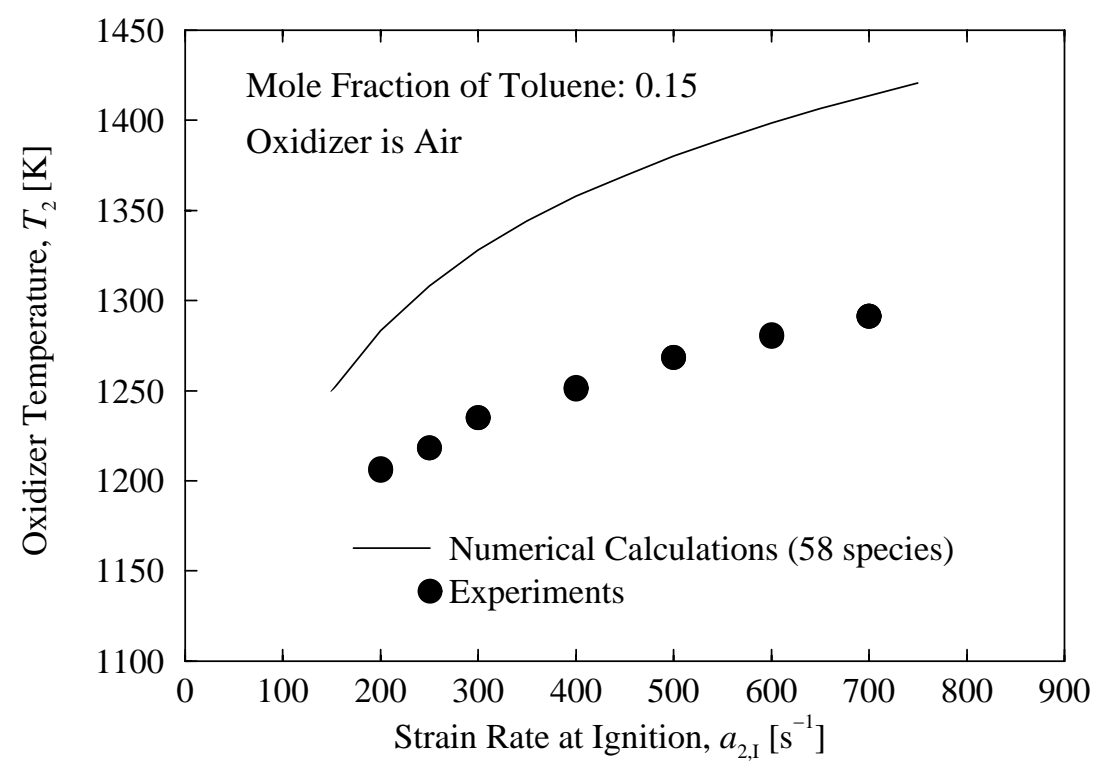

Figure 6: Oxidizer temperature at autoignition, $T_{2, I}$, as a function of the strain rate, $a_{2, I}$. The symbols represent measurements $[5,9]$. The solid line represents results of numerical calculations performed using the simplified chemical-kinetic mechanism made up of 58 species. 


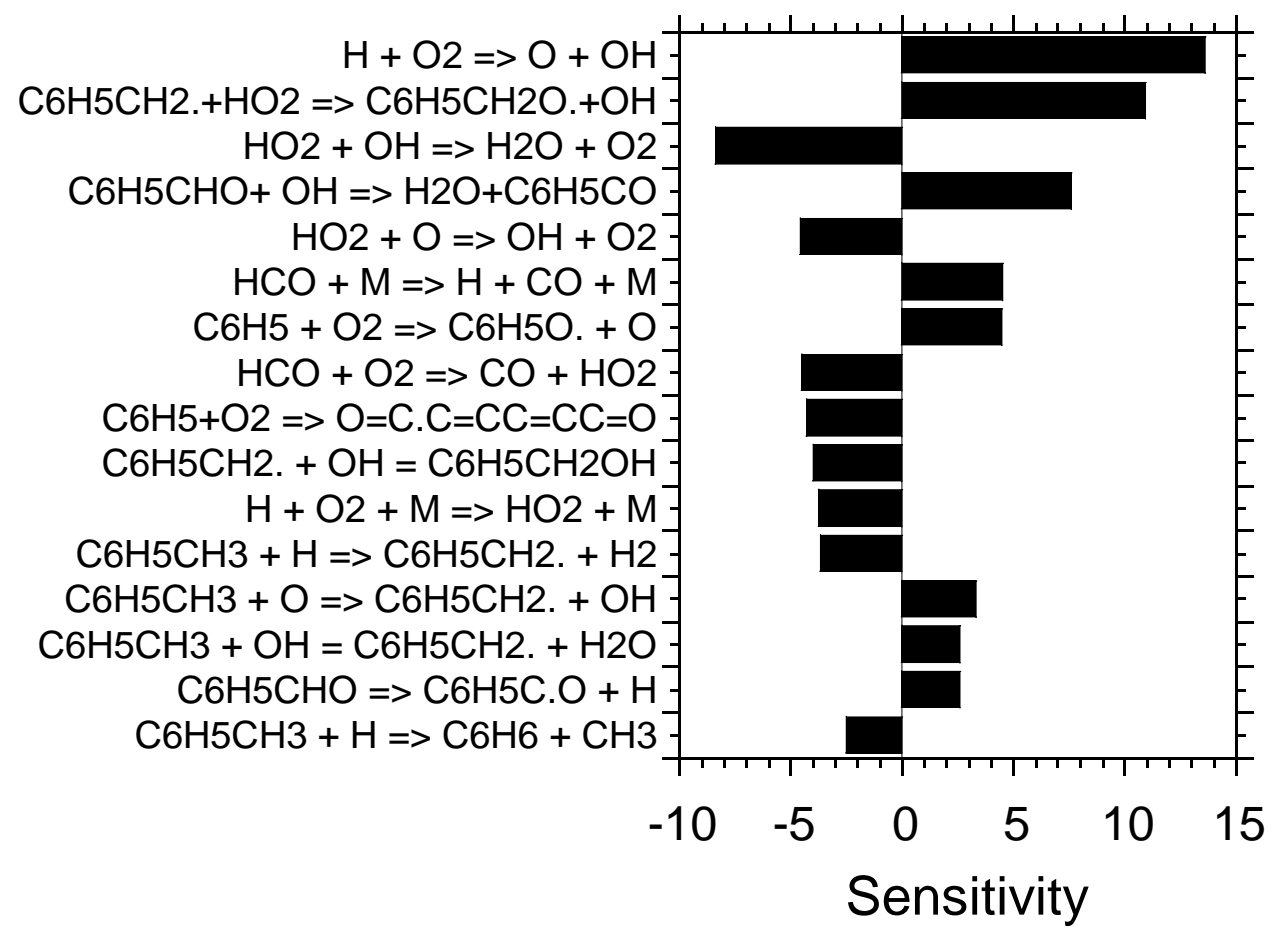

Figure 7: Sensitivity of the $\mathrm{OH}$ radical concentration to changes in individual rate constants under nonpremixed conditions near autoignition ( strain rate $=400 \mathrm{~s}^{-1}$, oxidizer temperature $T_{2}=1357 \mathrm{~K}$ ). 
accelerates the overall rate of reaction, while negative sensitivities indicate an increase in rate constant decreases the $\mathrm{OH}$ concentration and retards the overall rate of reaction. The $\mathrm{H}+\mathrm{O}_{2}$ chain branching reaction again gives very high sensitivity. The reaction benzyl radicals with $\mathrm{HO}_{2}$,

$$
\mathrm{C}_{6} \mathrm{H}_{5} \mathrm{CH}_{2} \cdot+\mathrm{HO}_{2}=\mathrm{C}_{6} \mathrm{H}_{5} \mathrm{CH}_{2} \mathrm{O} \cdot+\mathrm{OH}
$$

exhibits a particularly high sensitivity under counterflow ignition conditions. The reaction of benzaldehyde with $\mathrm{OH}$ shows a high positive sensitivity and promotes ignition.

The reactions that give significant sensitivity under nonpremixed conditions but not under flow reactor or shock tube conditions are reactions that involve the phenyl $+\mathrm{O}_{2}$ reaction:

$$
\begin{gathered}
\mathrm{C}_{6} \mathrm{H}_{5}+\mathrm{O}_{2} \rightleftharpoons \mathrm{C}_{6} \mathrm{H}_{5} \mathrm{O} \cdot+\mathrm{O}, \\
\mathrm{C}_{6} \mathrm{H}_{5}+\mathrm{O}_{2} \rightleftharpoons \mathrm{O}=\mathrm{C} \cdot \mathrm{C}=\mathrm{CC}=\mathrm{CC}=\mathrm{O} .
\end{gathered}
$$

An important uncertainty in the phenyl $+\mathrm{O}_{2}$ system is the branching ratio between the two product channels given above. The O-atom product channel is accelerating and the other ring-opening product channel is retarding (Fig. 7). The branching ratio depends on the relative barrier heights for the phenylperoxy radical going to $\mathrm{O}-\mathrm{O}$ bond breakage versus to ring opening [10].

\section{Publications and Technical Reports}

1. W. J. Pitz, C. K. Westbrook, R. Seiser, K. Seshadri, J. W. Bozzelli, I. Da Costa, R. Fournet, F. Billaud, and F. Battin-Leclerc, "Chemical-Kinetic Characterization of Combustion of Toluene," paper \# 252, $2^{\text {nd }}$ Joint Meeting of the US Sections of the Combustion Institute, Oakland California, March 25—28, 2001.

2. W. J. Pitz, R. Seiser, J. W. Bozzelli, I. Da Costa, R. Fournet, F. Billaud, F. BattinLeclerc, K. Seshadri, and C. K. Westbrook, "Chemical-Kinetic Study of Toluene Oxidation," paper \# 01F-28, Western States Section of the Combustion Institute, Fall 2001 Meeting, University of Utah, Salt Lake City, Utah, October 15-16, 2001.

\section{Participating Scientific Personnel}

The participating scientific personnel were 1) Professor K. Seshadri, and 4) Dr. R. Seiser. 


\section{References}

[1] R. J. Kee, F. M. Rupley, J. A. Miller, M. E. Coltrin, J. F. Grcar, E. Meeks, H. K. Moffat, A. E. Lutz, G. Dixon-Lewis, M. D. Smooke, J. Warnatz, G. H. Evans, R. S. Larson, R. E. Mitchell, L. R. Petzold, W. C. Reynolds, M. Caracotsios, W. E. Stewart, P. Glarborg, C. Wang, and O. Adigun. CHEMKIN collection, release 3.6. Reaction Design, Inc., San Diego, California, 2000.

[2] S. D. Klotz, K. Brezinsky, and I. Glassman. Modeling the combustion of tolune-butane blends. Proceedings of the Combustion Institute, 27:337-344, 1998.

[3] K. Seshadri and F. A. Williams. Laminar flow between parallel plates with injection of a reactant at high Reynolds number. International Journal of Heat and Mass Transfer, 21(2):251-253, 1978.

[4] R. Seiser, L. Truett, D. Trees, and K. Seshadri. Structure and extinction of non-premixed n-heptane flames. Proceedings of the Combustion Institute, 27:649-657, 1998.

[5] R. Seiser, K. Seshadri, E. Piskernik, and A. Liñán. Ignition in the viscous layer between counterflowing streams: Asymptotic theory with comparison to experiments. Combustion and Flame, 122:339-349, 2000.

[6] H. Pitsch. Entwicklung eines Programmpaketes zur Berechnung eindimensionaler Flammen am Beispiel einer Gegenstromdiffusionsflamme. Master's thesis, RWTH Aachen, Germany, 1993.

[7] N. Peters. Flame calculations with reduced mechanisms - an outline. In N. Peters and B. Rogg, editors, Reduced Kinetic Mechanisms for Applications in Combustion Systems, volume m15 of Lecture Notes in Physics, chapter 1, pages 1-13. Springer-Verlag, Heidelberg, 1993.

[8] D. R. Burgess. NIST XSenkplot: An interactive, graphics postprocessor for numerical simulations of chemical kinetics. http://www.cstl.nist.gov/div836/xsenkplot, Reacting Flow Group, Process Measurements Division, Chemical Science and Technology Laboratory, National Institute of Standards and Technology, 1996.

[9] R. Seiser, H. Pitsch, K. Seshadri, H. J. Curran, and W. J. Pitz. Experimental and numerical studies of extinction and autoignition of $n$-heptane. paper presented at the Fall Meeting of the Western States Section of the Combustion Institute, The University of California at Irvine, Irvine, California, October 25, 26, 1999.

[10] J. Bozzelli, N. Sebbar, W. Pitz, and H. Bockhorn. Reaction of phenyl radical with $\mathrm{O}_{2}$ : Thermodynamic properties, important reaction paths and kinetics. In Paper \#99, 2nd 
Joint Meeting of the US Sections of the Combustion Institute, Oakland, California, March 21-28 2001. 